\title{
The Use of Econometrics in Comparative Economic Systems
}

\author{
Comments to Peter Wiles' Review of F. L. Pryor, \\ Public Expenditures in Communist and Capitalisi Nations
}

By

Frederic L. Pryor

Peter Wiles' preceding review of my recent book on public expenditures in communist and capitalist nations raises three methodological issues that deserve comment.

(I) Regression analysis is best employed in testing specific hypotheses. In my analysis of defense expenditures I presented a model based on publicgood aspects of modern defense technology which led me to conclude that the ratio of defense expenditures to the G.N.P. is related to the absolute value of the G.N.P., rather than some other variable such as per capita income. The regressions with many different variables showed not only that my hypothesis explained a statistically significant proportion of the variation of the defense/G.N.P. ratio among nations but also that alternative explanatory variables were really quite unsatisfactory. Wiles presents an alternative model that is based on five, rather than one, independent variables, but since he does not put his model to a statistical test, he cannot claim it to be superior. Indeed, Occam's principle of simplicity puts a heavy burden of proof on any "literary" analysis with so many explanatory variables.

(2) One purpose of regression analysis is to discover quantitative relationships between variables we know to be associated - this is the reason for calculating income elasticities of various consumption goods. Thus my analysis of the relationship between military personnel and the population is not to prove this obvious relation but to examine the military personnelpopulation elasticity. My hypothesis about the public-good properties of current defense technology led me to conclude that such an elasticity would be much lower in the nineteenth than the twentieth century, a deduction which was supported by the quantitative analysis. Wiles' objection about my "trivial" results misses the purpose of the regression exercise.

(3) Regression analysis also permits some judgment to be made about the significance of changes in expenditures. In analyzing changes in the United States and Soviet defense expenditures, I discovered that in most years the year-to-year variations from the trend were extremely small. Predicting such variations ("turning points" in Wiles" language) is important only if the changes are larger than random; in the case of any important changes, my theory works quite well - at least in the period under examination. 